\title{
Practitioner Review: The assessment of bipolar disorder in children and adolescents
}

\author{
Argelinda Baroni ${ }^{1}$, Jessica R. Lunsford ${ }^{1}$, David A. Luckenbaugh ${ }^{2}$, Kenneth E. Towbin ${ }^{1}$, and \\ Ellen Leibenluft ${ }^{1}$ \\ ${ }^{1}$ Section on Bipolar Spectrum Disorders, Emotion and Development Branch, National Institute of \\ Mental Health, National Institutes of Health, Department of Health and Human Services, Bethesda, \\ MD, USA \\ ${ }^{2}$ Mood and Anxiety Program, National Institute of Mental Health, National Institutes of Health, \\ Department of Health and Human Services, Bethesda, MD, USA
}

\begin{abstract}
Background-An increasing number of youth are being diagnosed with, and treated for, bipolar disorder (BD). Controversy exists about whether youth with non-episodic irritability and symptoms of attention deficit hyperactivity disorder (ADHD) should be considered to have a developmental presentation of mania.
\end{abstract}

Method-A selective review of the literature related to this question, along with recommendations to guide clinical assessment.

Results-Data indicate differences between youth with episodic mania and those with non-episodic irritability in longitudinal diagnostic associations, family history, and pathophysiology. In youth with episodic mania, elation and irritability are both common during manic episodes.

Conclusions-In diagnosing mania in youth, clinicians should focus on the presence of episodes that consist of a distinct change in mood accompanied by concurrent changes in cognition and behavior. BD should not be diagnosed in the absence of such episodes. In youth with ADHD, symptoms such as distractibility and agitation should be counted as manic symptoms only if they are markedly increased over the youth's baseline symptoms at the same time that there is a distinct change in mood and the occurrence of other associated symptoms of mania. Although different techniques for diagnosing comorbid illnesses have not been compared systematically, it appears most rational to diagnose co-occurring illnesses such as ADHD only if the symptoms of the co-occurring illness are present when the youth is euthymic.

\section{Keywords}

Bipolar disorder; severe mood dysregulation; mania; diagnosis; assessment

Pediatric bipolar disorder (BD) is receiving increased attention from both clinicians and researchers. In the United States, the prevalence of the pediatric BD diagnosis in outpatient clinics increased 40-fold between 1994 and 2003 (Moreno et al., 2007). This upsurge may represent a true increase in prevalence, rectification of previous under-recognition, changes in

(C) 2008 The Authors Journal compilation @ 2008 Association for Child and Adolescent Mental Health.

Correspondence to Ellen Leibenluft, National Institute of Mental Health, Building 15K, MSC-2670, Bethesda, MD 20892-2670, USA; Tel: 301-496-9435; Fax: 301-402-6100; leibs@ mail.nih.gov.

Conflict of interest statement: No conflicts declared. 
conceptualization of the disorder, or the inappropriate application of the diagnosis to youth with other illnesses. In particular, the latter two possibilities arise because there is considerable disagreement as to the clinical circumstances in which the diagnosis of BD should be applied to youth. Specifically, a major question is whether children and adolescents with severe, nonepisodic irritability and symptoms of ADHD should be considered to have a developmental presentation of mania.

Here, we address this question in the context of a selective literature review. That is, rather than comprehensively reviewing all of the published literature, we focus on data relevant to the issue of whether youth with severe, non-episodic irritability differ in longitudinal course, family history, and pathophysiology from those who clearly meet DSM-IV criteria for BD. This review thus includes our own work relevant to this question, as well as relevant data from other research laboratories.

Our primary goal is to use the data to provide guidance to clinicians as to the circumstances under which they should assign the BD diagnosis to a child or adolescent. Specifically, we will argue that, at this time, the diagnosis of BD should be reserved for youth who have a history of one or more distinct episodes of mania or hypomania meeting full DSM-IV duration criteria (i.e., 4 days for hypomania and 7 days for mania). This recommendation is consistent with guidelines from both the American Academy of Child and Adolescent Psychiatry (AACAP, 2007) and British National Institute for Health and Clinical Excellence (http://www.nice.org.uk) and, while certainly more research is needed on the question, is consistent with the current available data, as reviewed below.

We begin by reviewing the DSM and ICD-10 criteria for bipolar disorder. Given our recommendation that the diagnosis of $\mathrm{BD}$ be reserved for those youth with distinct episodes of mania or hypomania, we focus in particular on the DSM-IV definition of an episode. Next, we describe data we have gathered in youth with severe mood dysregulation, a clinical syndrome that we defined to ascertain youth in whom the diagnosis of BD is controversial (Leibenluft, Charney, Towbin, Bhangoo, \& Pine, 2003). These data form the basis for our recommendation that only youth with distinct episodes receive the diagnosis of mania and, by extension, BD. We then discuss the controversial issue of whether elation or irritability is characteristic of mania in youth. Based on the available data, we conclude that, in a sample selected for the presence of distinct manic episodes, a history of euphoria is extremely common, although irritability is also frequently seen. Finally, we conclude by describing how clinicians can assess patients for BD; in this way, we provide methods for operationalizing our recommendations. In this section, we include recommendations for assessing co-occurring illnesses, and discuss differential diagnosis.

\section{Key practitioner messages}

The diagnosis of bipolar disorder, in youth as well as adults, should only be made in the presence of identifiable manic or hypomanic episodes.

In DSM-IV, ICD-10, and NICE Guidelines, manic episodes must last for 7 days or more and include a distinct change from baseline mood with concurrent alterations in behavior.

DSM-IV and ICD-10 support a diagnosis of hypomania in children if episodes last at least four days.

There is no single optimum diagnosis for youth with severe, non-episodic irritability. Current evidence suggests that such irritability may be a variant of depression. 
Youth with severe, non-episodic irritability differ from those with bipolar disorder in longitudinal course, family history, and performance on many, although not all, tasks linked to pathophysiology.

Of note, throughout this review, we use the term 'youth' to apply to both children and adolescents. While the bulk of the controversy regarding the diagnosis of BD has centered on prepubertal children, similar questions have arisen regarding adolescents, and much of the relevant literature does not differentiate amongst these age groups; this is clearly an important area for future research.

\section{DSM-IV-TR and ICD-10 criteria: focus on episodes}

\section{The criteria and definition of an episode}

In the US, BD is currently diagnosed in both children and adults according to the criteria specified in DSM-IV (American Psychiatric Association, 2001), while in Europe the ICD-10 (World Health Organization, 1992) is used. The criteria for a manic episode in DSM-IV and ICD-10 are presented in Tables 1 and 2, respectively.

According to DSM-IV, BD is characterized by episodes of mania, hypomania, or mixed state, and depression. Specifically, a manic or mixed episode alone is sufficient to diagnose BD I, while at least one hypomanic plus one major depressive episode is needed for BD II. On the other hand, ICD-10 always requires at least two mood episodes for BD, one of which must be hypomania, mania, or mixed. If mania is present, the diagnosis of BD I is assigned, while if only hypomania is present, the diagnosis of BD II is assigned. In general, however, the criteria in ICD-10 and DSM-IV are quite similar. Importantly, both require clear, distinct episodes with a significant change from the individual's baseline functioning, and the same number and type of symptoms during episodes. Here we focus specifically on the criteria for a manic episode, since the recent controversy in child psychiatry has focused on mania rather than depression. It is important to note that one specifically makes a diagnosis of a manic episode in DSM-IV, not mania per se. Therefore, according to DSM-IV, if one cannot identify distinct episodes, one cannot diagnose mania or hypomania and, by extension, one cannot diagnose BD.

\section{Areas for future research}

Longitudinal studies comparing the course and outcome of youth with bipolar disorder and severe, non-episodic irritability.

fMRI studies to compare pathophysiology of bipolar disorder and severe mood dysregulation.

Studies of candidate endophenotypes (pathophysiological risk markers) to allow the identification of youth who are most likely to develop bipolar disorder.

Studies comparing how different diagnostic criteria and assessment techniques influence findings regarding the course, family history, and pathophysiology of youth diagnosed with bipolar disorder.

There are two components to the definition of an episode. First, the ' $\mathrm{A}$ ' criterion requires a 'distinct period' of abnormal mood, lasting the requisite number of days and then returning to either a euthymic or at least subsyndromal state. Thus, if a clinician is to diagnose a manic episode, s/he must have identified at least one identifiable period of time when the patient's mood was distinctly different from his or her baseline. While the DSM-IV specifies that the abnormal mood must be 'elevated, expansive, or irritable' (for a discussion of this point, see 
below), it does not specify how persistent the mood change must be during the four (for hypomania) or seven (for mania) days. In contrast, the criteria for a major depressive episode specify that the abnormal mood state must be present most of the day, nearly every day during the episode. In our group, we adopt a similar convention for manic or hypomanic episodes, and recommend that clinicians do the same.

The second component of an episode is that, concurrent with the change in mood, the patient must have experienced the requisite number of ' $\mathrm{B}$ ' criteria. Therefore, to apply the DSM criteria, the clinician should identify a period of a distinct mood change, and then ascertain whether sufficient ' $\mathrm{B}$ ' criteria are present at the same time as the mood change (see Assessment for more details). Specifically, the symptoms should have their onset or, in the case of symptoms overlapping with other illness, worsening, at the same time. This technique is consistent with the methods for applying the SCID (Structured Clinical Interview for DSMIV Axis I Disorders; First, Spitzer, Gibbon, \& Williams, 1995) semi-structured diagnostic interview used in most psychiatric research in adults, as well as the K-SADS-PL (Schedule for Affective Disorders and Schizophrenia for School Age Children-Present and Lifetime version; Kaufman et al., 1997), designed for use in youth. The DSM-IV requires that the episode (i.e., the mood change and associated symptoms together) be severely impairing in the case of mania, and noticeable to others in the case of hypomania.

\section{Does DSM-IV BD exist in children and adolescents?}

Using these assessment methods, can youth be identified who meet DSM-IV criteria for mania or hypomania? The answer to this question is clearly yes. The COBY (Course of Bipolar Youth) study, using assessment techniques like those described above, identified 255 children and adolescents with BD I and 30 with BD II, with a mean age of $12.9 \pm 3.2 \mathrm{y}$ (Axelson et al., 2006; Birmaher et al., 2006). These subjects displayed a clearly episodic course: most (70\%) of the subjects recovered from their index episode but $50 \%$ had at least one syndromal recurrence, usually depression. However, it is unclear exactly how common BD is in prepubertal children or, for that matter, adolescents. In the community-based Great Smoky Mountains Study $(N=1015)$ there were no cases of mania in children age 9-13 and the 3month prevalence of hypomania was extremely low $(.10 \pm .6 \%)$ (Costello et al., 1996).

Importantly, it is not yet clear whether and to what extent BD presents with different clinical features at different ages, as many studies collapse results for adolescents and children together, and few studies compare adults with BD to youth with the illness. The largest analysis of this latter question was published by Birmaher et al. (2006), who compared the clinical course of children in the COBY study $(N=152)$ to that of adults with BD in the NIMH Collaborative Depression Study ( $N=146)$ (Judd et al., 2002). Youth with BD I were symptomatic more often than adults (58.9\% vs. $47.3 \%$ of weeks), spent significantly more time in mixed and cycling episodes ( $28.9 \%$ vs. $5.9 \%$ of weeks), and had more changes in mood polarity per year (15.7 \pm 17.5 vs. $3.5 \pm 7.4$ ) (Birmaher et al., 2006; Judd et al., 2002).

In addition, other studies indicate that, compared to children, adolescents may display symptoms and course that more closely resembles that of adults (Kyte, Carlson, \& Goodyer, 2006; Masi et al., 2006) including onset with depressive episodes, fewer mixed episodes and less cycling (Findling et al., 2001; Kyte et al., 2006). However, overall, while there are some data indicating considerable consistency of the clinical picture from school-age children through to adulthood (Birmaher et al., 2006; Findling et al., 2001; Masi et al., 2006), considerably more research is needed on this question. 
How short can an episode be, and the question of bipolar disorder not otherwise specified (BD NOS)?

Is the DSM justified in setting a minimum of 4 days for a hypomanic episode? This has been an area of active debate in the adult psychiatric literature (Angst \& Cassano, 2005), and definitions using different episode lengths have not been compared systematically, so further research is needed. Indeed, one major research group in pediatric BD, that of Geller et al., recommends the adoption of definitions for episodes and cycles, across both pediatric and adult bipolar research, (Geller, Tillman, \& Bolhofner, 2007; Tillman \& Geller, 2003). In a series of influential studies using these methods (e.g., Geller, Tillman, Craney, \& Bolhofner, 2004), episodes must last at least 2 weeks, and an episode can consist of cycles as short as 4 hours. In these studies, it appears as if the onset and offset of each symptom is ascertained separately, rather than beginning with a putative episode and ascertaining whether each ' $\mathrm{B}$ ' criterion is met during that specified time frame (Geller, Warner, Williams, \& Zimerman, 1998a; Geller et al., 1998b). While all of the ' $\mathrm{B}$ ' criteria must be present at the same time as the mood change, again it appears as if the onset of the various ' $\mathrm{B}$ ' criteria need not be close in time to each other, nor close in time to the onset of the mood symptoms (Geller et al., 2006). It would be important to compare children diagnosed using these criteria and techniques to those diagnosed using other techniques.

When the patient's episodes are shorter than 4 days long, the diagnosis of bipolar disorder not otherwise specified (BD NOS) is sometimes assigned. AACAP guidelines (AACAP, 2007) recommend that BD NOS be assigned to youth with one of two clinical presentations: 1) clear manic episodes lasting less than 4 days, or 2) a baseline level of functioning characterized by 'manic-like symptoms', often presenting with ADHD or other disruptive behavior disorders, but without clear episodes. With regard to the first group, the COBY study identified 158 youth classified as BD NOS, almost all of whom (96\%) did not meet full DSM-IV criteria because their episodes were too short, usually approximately 2 days long (Birmaher et al., 2006; pers. com., D. Axelson). These BD NOS patients showed similar clinical features and family history to those with BD I, and up to a third of them converted to BD I or II within a few years (Birmaher et al., 2006). On the other hand, as we will discuss below under Severe Mood Dysregulation, youth in the second group above (i.e., those suffering from non-episodic irritability) appear to be at high risk for depression in early adulthood (Brotman et al., 2006; Leibenluft, Cohen, Gorrindo, Brook, \& Pine, 2006). These data suggest that the AACAP guidelines are subsuming two relatively distinct populations into the BD NOS category.

Based on these data, we recommend that the diagnosis of BD NOS be assigned only to youth with clear episodes of mania too short to meet full DSM-IV duration criteria for mania or hypomania. This recommendation is based on the observation that such youth are at very high risk to ultimately meet DSM-IV criteria for BD I or II. Further, we recommend that the diagnosis of BD NOS be reserved for patients with episodes that are at least 2 days long, because it is difficult to ascertain decreased need for sleep, as well as meaningfully increased goaldirected activity (e.g., as opposed to developmentally appropriate excitement) and other 'B' symptoms, with shorter episodes. Even if these relatively restrictive recommendations are followed, it is possible if not likely that many of the subjects meeting even these criteria for BP-NOS will not go on to develop BD I or II. Clearly, more longitudinal data are needed to determine the validity of these recommendations. In addition, it will be important to ascertain whether and how the pathophysiology of manic or hypomanic episodes lasting a week differs from those lasting 4 days, 4 hours, or other durations.

\section{Severe mood dysregulation: non-episodic irritability}

As noted above, some researchers have suggested that, rather than having distinct mood episodes, children with BD either have very rapid cycles (perhaps several a day), or a non- 
episodic and relatively invariant course (AACAP, 2007; Biederman, Klein, Pine, \& Klein, 1998; Findling et al., 2001; Geller et al., 1998b, 2004; Wozniak et al., 1995). In essence, the debate centers on whether extremely irritable children without distinct episodes, but with symptoms similar to those seen in ADHD, should be considered to have a developmental presentation of BD. To provide a framework for research on this question, Leibenluft et al. (2003) operationalized criteria to capture the population whose diagnosis is in doubt, and named the syndrome severe mood dysregulation (SMD).

\section{Criteria for severe mood dysregulation (SMD)}

In the criteria for SMD, irritability is defined specifically, and with a high threshold (Table 3). Patients must have 'developmentally inappropriate increased reactivity to negative emotional stimuli' at least three times per week, as well as sadness or anger most days, most of the time, noticeable to others. Thus, SMD youth have frequent emotional outbursts, and between outbursts they exhibit persistent negative-valence mood. The SMD symptoms must be nonepisodic, in the sense of being present for at least one year beginning before age 12 (to avoid confusion with developmental adolescent irritability), without any symptom-free period longer than 2 months. Subjects must exhibit at least 3 of the 'B' criteria of mania that are seen frequently in youth with ADHD (distractibility, agitation, pressured speech, intrusiveness, insomnia, flight of ideas/racing thoughts). Irritability must be severely impairing in at least one of three settings (home, school, peers) and at least mildly impairing in a second setting; thus, youth who are irritable only at home are excluded. Exclusion criteria include psychosis or any episode longer than a day that, except for the duration criterion, meets criteria for hypomania. In sum, these criteria capture youth with severely impairing non-episodic irritability and hyperarousal. Clinicians with masters' level training and above can be trained to achieve kappas $>.9$ in identifying such youth and differentiating them from those with DSM-IV BD (Dickstein et al., 2007;Brotman et al., 2007; Rich et al., 2007,in press).

\section{Do youth with SMD develop DSM-IV BD in adulthood?}

Although we have not yet followed a cohort of SMD youth long enough to answer this question definitively, we obtained pilot data by performing post-hoc analyses of two longitudinal, community-based data sets. In one analysis, using the Great Smoky Mountain data set $(N=$ 1420 ), we identified youth meeting SMD criteria at age 10.6 $\pm 1.4 \mathrm{y}$ and ascertained that they had elevated risk ( $\mathrm{OR}=7.2, \mathrm{CI}=1.3-38.8, p=.02)$ for MDD at age 18.3 $\pm 2.1 \mathrm{y}$ (Brotman et al., 2006). There were too few patients meeting DSM-IV criteria for BD in the Great Smoky Mountain cohort to address directly associations between SMD in youth and BD in early adulthood, and of course those SMD youth with MDD at age 18 could go on to develop BD at a later date. Nonetheless, given the fact that there is a significant peak of BD onset in mid to late adolescence (Goodwin \& Jamison, 2007), one might have expected to begin to see a number of such 'conversions' by age 18 .

Our second analysis used somewhat different methods but arrived at a very similar conclusion. Here, we used the Children in the Community study to determine whether chronic and episodic irritability are distinct constructs, and to identify associations between chronic vs. episodic irritability in adolescence and DSM-IV diagnoses in early adulthood (Leibenluft et al., 2006). We found that chronic and episodic irritability differed in their associations with age and sex and, indeed, that correlations within irritability type over 2 years were higher than correlations between irritability types measured at the same time point. For example, the correlation between episodic irritability measured at mean age $13.8 \pm 2.6 y$ (time 1 ) and again at mean age $16.2 \pm 2.8 \mathrm{y}$ (time 2) was .79, while the correlation between chronic and episodic irritability measured simultaneously at time 1 was significantly lower at .34. Further, episodic irritability at time 1 predicted mania at time 2, whereas chronic irritability at time 1 predicted ADHD at time 2 and major depressive disorder (MDD) at time 3 (mean age $22.1 \pm 2.7 \mathrm{y}$ ). The latter 
finding is consistent with our analysis of the Great Smoky Mountain study, as well as with other literature showing associations between chronic irritability in youth and MDD in early adulthood (Burke, Loeber, Lahey, \& Rathouz, 2005). Thus, these data would lead one to conclude that SMD youth should not receive the diagnosis of $\mathrm{BD}$, because longitudinal course is likely to differ between youth exhibiting the clinical presentation of SMD from those exhibiting distinct manic episodes.

\section{Family history and pathophysiology}

Another relevant study compared psychiatric diagnoses in the parents of SMD vs. BD youth. If SMD is a developmental phenotype of $\mathrm{BD}$, then youth with SMD should have strong family histories of BD. Specifically, the literature suggests that, compared to those without a family history of BD, subjects with a first-degree relative with BD have a 4- to 13-fold increased risk of developing $\mathrm{BD}$, whereas the risk is increased approximately 2.5 -fold when a second-degree relative is affected (Lapalme, Hodgins, \& LaRoche, 1997; Mortensen, Pedersen, Melbye, Mors, \& Ewald, 2003; Youngstrom \& Duax, 2005). In a sample of youth with BD from the COBY study $(N=192$, age $9.5 \pm 2.4 \mathrm{y}), 37.5 \%$ had a first-degree relative with mania (Rende et al., 2007).

In a pilot study where the parents of SMD and BD youth were diagnosed by an interviewer blind to proband diagnosis, $33.3 \%$ of the parents of youth with BD met criteria for BD, whereas $2.7 \%$ of the parents of youth with SMD met criteria for BD $(\mathrm{OR}=17.96, \mathrm{CI}=1.89-170.77$, $p=.01$; Brotman et al., 2007). Thus, congruent with longitudinal data, family history data would lead one to believe that SMD youth should not receive the diagnosis of BD.

With regard to the question of shared pathophysiology between SMD and BD, the picture is more mixed. Since irritability has been such an important focus in pediatric BD research, we designed a task that would frustrate subjects, and administered it to SMD and BD patients and controls while measuring evoked response potentials (ERPs) (Rich et al., 2007). When frustrated, both SMD and BD youth reported more irritability than did control subjects. However, the pathophysiological correlates of that frustration differed, in that BD youth showed deficits in executive attention (as measured by parietal P3), whereas SMD youth showed deficits in early sensory processing (as measured by central and temporal N1). However, there does appear to be some shared pathophysiology between SMD and BD, in that both patient groups exhibit deficits in their ability to label face emotions. This deficit is generalized across emotions (Rich et al., in press) and is not seen in youth with ADHD or those with MDD and anxiety disorders (Guyer et al., 2007).

These mixed pathophysiological data are best understood in light of the complex genetics underlying BD (Goodwin \& Jamison, 2007). Whereas BD is now conceptualized dichotomously (one does or does not have BD), eventually it is likely that the illness will be viewed dimensionally. Assume, for argument's sake, that there are 15 genes that confer risk for BD. How does one categorize an individual with two risk-related alleles? It is possible that there are some shared genetic mechanisms between SMD and BD, along with many important genetic differences. Nonetheless, given that the longitudinal, family history, and pathophysiological data described above identify important differences between the two groups, we do not feel that it is currently justified to diagnose youth with non-episodic irritability and ADHD symptoms as having BD.

\section{Where do SMD youth fit in the DSM?}

Youth with a clinical presentation similar to that of SMD have been called 'nosologic orphans', because they do not fit neatly into any DSM category (Carlson, 1998). Most of these youth meet criteria for ODD and/or CD, as well as ADHD (Rich et al., 2007, in press; Dickstein et 
al., 2007); however, CD criteria make no reference to irritability and the criteria for irritability in ODD are not as precise as those for SMD. In essence, SMD youth could be viewed as having a particularly severe form of ODD, accompanied by ADHD. In addition, approximately $30 \%$ of SMD youth have had an episode of MDD by age 12 and about $60 \%$ display an anxiety disorder. Since SMD youth are at high risk to either have, or eventually develop, MDD, and given the strong familial overlap between BD and MDD (Goodwin \& Jamison, 2007), the most appropriate conceptualization for SMD may be a form of irritable depression, but many SMD youth do not fit current DSM-IV criteria for a depressive illness.

Importantly, approximately $70 \%$ of SMD youth are male, compared to the equal gender distribution in BD youth (Rich et al., 2007, in press; Dickstein et al., 2007; Birmaher et al., 2006). We suggest that the upsurge in youth receiving the diagnosis of BD (Moreno et al., 2007) may reflect a trend of applying the BD label to youth with a clinical presentation of SMD, in part because of the lack of a clear-cut diagnosis in DSM-IV for SMD youth. This suggestion is consistent with Moreno et al.'s (2007) observation that youth receiving the diagnosis of $\mathrm{BD}$ in recent years are disproportionately male and have very high rates of ADHD. Clearly, this is a problem that should be addressed as the field begins deliberations on DSM$\mathrm{V}$. The lack of a DSM 'home' for SMD youth is particularly problematic because data indicate that these youth are severely impaired as those with DSM-IV BD, whether impairment is measured by mean number of medications or hospitalizations, or by mean CGAS score.

\section{Elation vs. irritability}

In addition to the question of whether youth with $\mathrm{BD}$ have distinct manic episodes, another major point of disagreement in the literature is whether the hallmark mood disturbance of mania in children is severe irritability and dysphoria, rather than euphoria and elated mood (Mick, Spencer, Wozniak, \& Biederman, 2005; Biederman et al., 1998; Wozniak et al., 1995; Geller et al., 1998b). In this context, the COBY study reported that euphoria was present in $92 \%$ of children with BD I, whereas irritability was found in $84 \%$, indicating that co-occurring euphoria and irritability are characteristic of mania in youth with BD (Axelson et al., 2006). Thus, if one selects for distinct manic episodes, as was done in the COBY study and studies of adults with $\mathrm{BD}$, one finds high rates of euphoria. Indeed, the COBY data are consistent with what one would see in a sample of adults with mania, most of whom have a lifetime history of euphoric mania, but many of whom also have irritable manias, and a minority of whom have a lifetime history of only irritable mania (Cassidy, Pieper, \& Carroll, 2001b). In addition, it is important to recognize that even adults with classic euphoric mania are not persistently euphoric. During mania, euphoria often rapidly gives way to irritability; an adult with euphoric mania who is denied a request typically responds with irritable and possibly even aggressive behavior.

Major pediatric research groups have divergent views of the primacy of irritability vs. elation in mania. Geller and coworkers consider elation and grandiosity to be cardinal symptoms of mania, and require the presence of at least one of these for the diagnosis of BD (e.g., Geller et al., 2004). Similarly, the NICE guidelines state that, in children and adolescents, the diagnosis of mania should not be made unless euphoria is present (http://www.nice.org.uk), and the diagnosis of bipolar II should not be applied to children or adolescents.

In contrast, Biederman and coworkers consider marked irritability to be the hallmark symptom of pediatric BD. In their work, it appears as if youth are considered to meet DSM-IV criteria for mania if 'super-angry/grouchy/cranky' irritability is present, even when it does not constitute an episodic change from baseline (Mick et al., 2005). Youth ascertained with these criteria were predominately male (78-84\%, depending on the sample) and exhibit extreme irritability and explosiveness, with only occasional euphoria (Biederman, Faraone, Chu, \& Wozniak, 1999; Biederman et al., 2004, 2005; Wozniak et al., 1995). For example, in 129 
children with BD (mean age $8.7 \pm 2.2$ years), only $33 \%$ of the children had euphoria while manic, while $92 \%$ had irritability (Biederman et al., 2005).

We adopted a strategy similar to Geller and coworkers in our phenotyping scheme for pediatric mania (Leibenluft et al., 2003), where we required that youth with 'narrow-phenotype' mania have a history of euphoria or grandiosity in at least one of their manic or hypomanic episodes. We considered youth with episodic irritable mania to be an 'intermediate phenotype.' BD youth in our studies meet the narrow phenotype criteria, i.e., distinct, full-direction episodes with euphoria, which is thus somewhat more restrictive than DSM-IV. In specifying these categories, we assumed that it would be difficult to differentiate youth with distinct episodes from those without (in other words, we wanted the extra 'insurance' of requiring elation to differentiate BD from SMD), and there were little data relevant to the question of whether to consider irritable mania analogous to euphoric mania. Since 2003, however, data from the COBY study (Axelson et al., 2006), described above, indicate that most youth with episodic manic exhibit euphoria, and data from our post-hoc analysis of data from the Children in the Community study (Leibenluft, Cohen, Gorrindo, Brook, \& Pine, 2006) show an association between episodic irritability and mania. In addition, with regard to the issue of differentiating reliably youth with episodes from those without, in our experience it is not difficult to train experienced masters or doctorate level clinicians to do so (kappa $\geq .9$, Dickstein et al., 2007; Rich et al., 2007, in press; Guyer et al., 2007). Therefore, based on the available data and our own clinical experience, we no longer recommend that clinicians restrict the diagnosis of $\mathrm{BD}$ to youth with euphoric episodes. However, we find that, if one ascertains youth with distinct manic episodes, the vast majority of them will have exhibited euphoria during at least one of their episodes. Nonetheless, more research is needed on this important question.

\section{Assessment of mania in youth}

Here, consistent with the data presented above, we provide guidelines for assessing manic episodes. Before discussing details of the assessment, we note that it is important that child and parent (or caregiver) be interviewed both separately and together. Basically the same set of questions should be asked to both. Then, a meeting with parent and child together can be used to resolve any inconsistencies (for example, a parent may report that a child was euphoric because he was giggling excessively when punished, while the child may report that he was giggling from embarrassment). While this recommendation is in keeping with standard practice in child psychiatry (AACAP, 2007), only limited data exist regarding the impact of informant on diagnosis in the assessment of pediatric mania. Some data indicate that parents' reports are more valid than youth's or teachers' in establishing the occurrence of manic symptoms (Youngstrom, Meyers, Youngstrom, Calabrese, \& Findling, 2006), while others find that parents may be less likely than youths to report that the youth is experiencing characteristic manic symptoms such as elation, grandiosity, flight of ideas, and racing thoughts (Tillman et al., 2004). In addition, youth can provide important information about their suicidal or homicidal ideation or attempts, hallucinations or delusions, and about abuse that they may have suffered (AACAP, 2001; Youngstrom et al., 2006). In our clinical experience, parents are more likely than their children to describe the child's irritability, while parents often underestimate the severity of their child's anxiety symptoms, grandiose thinking, racing thoughts, and, less commonly, the extent of their child's psychotic symptoms.

Consistent with the diagnostic criteria and recommendations described above, screening questions for mania (or depression) should inquire about distinct periods of mood change associated with the other symptoms of a mood episode (i.e., sleep disturbances, psychomotor activation, and other changes in behavior and cognition) (APA, 2001; Kaufman et al., 1997). 
Specifically, to determine the occurrence of a manic episode, the clinician should ascertain whether the child and parent can identify a period of time, lasting at least 4 days for hypomania or 7 days for mania, during which the youth displayed euphoria or increased irritability that was unusual for him or her, and accompanied by a sufficient number of ' $\mathrm{B}$ ' criteria (see Table 1) that were uncharacteristic or distinctly more severe than usual during this time. Euphoria and/or irritability must be highly conspicuous during this period, meaning it is present most, but not necessarily all, of the time during the episode.

Whether the severity of a symptom is severe enough to be considered above diagnostic threshold is an important and potentially thorny decision. Also, when evaluating pediatric patients, clinicians should consider developmental differences: how does euphoria in an 8year-old differ from euphoria in a 12-, 16-, 25-, or 40-year-old, and how do all the latter groups differ from each other? The decision is further complicated because developmental age is not synonymous with chronological age, and such assessments are particularly challenging in children with atypical development. However, in this instance, the fact that an episode must represent a distinct change from that youth's own baseline provides a helpful framework for the clinician. The evaluator should ask parents to compare the youth's current state (or state during the putative episode) to the youth's typical mood, behavior, and level of function. In addition, the episode should be severely impairing in the case of mania, and noticeable to others in the case of hypomania. Therefore, one would expect that it would be difficult for a child to continue in an ordinary school program during a manic episode, and a hypomanic episode should have received comment from teachers and/or peers, as well as from parents.

With regard to the threshold for elation, it may help to consider whether the youth's elation is any greater than his or her positive affect during a trip to Disneyland or on Christmas morning. In mania, elation should be inappropriate to context, unusual for that child, and having its onset at about the same time as criteria 'B' symptoms. Similarly, in a youth with chronic irritability, irritable mood would only count toward the 'A' criterion of mania if, during the specified episode, the youth was distinctly more irritable than at his/her baseline. Questions that can be asked about mood changes include 'Was Johnny different from way he usually is? Was he uncharacteristically and inappropriately happy? Or much more irritable than usual? Did teachers notice the change? Did it cause problems?' It is always important to get details in order to increase reliability, e.g., 'Did you have more fights than usual at school? Did your family complain that you were crankier that usual? Did your friends say that you were getting really crabby?'

Once episodes are identified, the interviewer should inquire whether criterion 'B' symptoms occurred at the same time as the mood changes. Three symptoms are required if the predominant mood is elation, four symptoms if the mood is irritable. As with elation, increased self esteem or grandiosity should represent a change from baseline, be developmentally inappropriate, and either noticeable to others (in the case of hypomania) or impairing (in the case of mania). There are many instances where a young child who pretends to be an astronaut or says he could become an astronaut in the future would not be considered grandiose. However a child who is usually cautious but, at a time when his mood and activity level are different from usual, wants to jump from the top of a flight of stairs believing 'he can fly and nothing can hurt him' can be considered grandiose.

A common clinical question is whether a youth who, as a clear manifestation of psychopathology challenges the teacher, or claims to be smarter than the teacher, is exhibiting grandiosity or oppositional behavior. Here again, it is important to weigh: 1) whether the behavior constitutes a distinct change from baseline, and 2) whether there are a sufficient number of new-onset concurrent symptoms. Thus, if a youth often defies his or her teacher, this is more likely to be oppositional behavior than a symptom of mania. On the other hand, if 
a typically shy youth begins openly challenging his or her teacher, at the same time that he or she begins to exhibit a decreased need for sleep and increased motor activity, that is much more likely to be a symptom of mania or hypomania.

With regard to sleep patterns, it is important to differentiate decreased need for sleep (i.e., the patient sleeps less than usual for him or her, is not tired, and does not nap to compensate for decreased nighttime sleep), from insomnia (i.e., an individual wants to sleep but cannot, and is tired the next day). Decreased need for sleep is rather specific to mania, whereas insomnia is common in a number of psychiatric illnesses. Decreased need for sleep was present in the majority (83.2\%) of youth with BDI in the COBY study (Axelson et al., 2006) and, in another study, discriminated children with ADHD from those with BD (Geller et al., 2002). Often, children are quite active in the middle of the night when they are in a manic or hypomanic episode (rearranging furniture, playing videogames, etc.). Again, a sleep pattern that is a symptom of mania can be differentiated from typical adolescent sleep phase delay when it is a change from the adolescent's typical pattern, and when the adolescent sleeps less than is typical for him or her and is not tired over the next day or so.

\section{Overlap between ADHD and mania, and the assessment of co-occurring conditions}

A number of the remaining ' $B$ ' criteria of mania (distractibility, agitation, increased goaldirected activity, pleasure-seeking, racing thoughts, pressured speech) can be viewed as overlapping with the diagnostic criteria for ADHD. This complicates the differential diagnosis of mania in youth while also raising important questions as to how one can diagnose cooccurring ADHD when distinct manic episodes are clearly present. However, the historical view (operationalized in the DSM) that BD is an episodic illness makes both of these issues significantly more tractable. Specifically, in a youth with $\mathrm{BD}$, the diagnosis of co-occurring ADHD (or any other co-occurring illness, such as an anxiety disorder) is made based on symptoms present during a time when the patient is not hypomanic, manic, or depressed. Thus, when interviewing families, the clinician should identify, in addition to putative episodes of mania and depression, a period when the youth was euthymic or had only subsyndromal mood symptoms. The clinician should then inquire about whether the symptoms of anxiety disorders, ADHD, and other possible co-occurring illnesses were evident during this euthymic period. Reports in the literature suggest that up to 70-90\% of children and 30-40\% of adolescents with BD present with co-occurring ADHD (Singh, DelBello, Kowatch, \& Strakowski, 2006).

However, it is often unclear whether the guidelines described above were followed in assessing co-occurring illnesses, or instead whether these data might be confounded by overlap between the symptoms of ADHD and those of mania and/or depression. Research is needed to compare the validity of different techniques for identifying comorbid illnesses.

Conversely, in a youth with ADHD, a symptom such as distractibility or 'pleasure seeking', in the form of engaging in risky behavior, should 'count' toward the diagnosis of mania only if the severity of the symptom increased significantly at the same time that the child's mood was abnormal. Once again, because $\mathrm{BD}$ is characterized by distinct episodes, this differentiation becomes more feasible; the youth's symptoms during a putative episode can be compared to his or her usual behavior. In addition, the severe behavioral problems that adolescents with ADHD can develop in response to the combined stress of social pressures, academic demands, and puberty should be distinguished from the onset of mania. The latter should be more abrupt and characterized by the onset of a number of new symptoms at once.

\section{Differential diagnosis}

It is important to differentiate $\mathrm{BD}$ from $\mathrm{ADHD}$, psychotic disorders, and substance use disorders. Using the techniques described above, chronic conditions such as ADHD and ODD, even when characterized by severe irritability and oppositionality, can be differentiated from 
an episodic one (mania). Psychosis in the context of BD can be differentiated from schizophrenia and schizoaffective disorder if one is mindful that, in BD, psychotic symptoms must appear exclusively during the same time as severe mood symptoms. However, it must be acknowledged that this determination (i.e., whether psychotic and mood symptoms occurred concurrently) can be a difficult one to make retrospectively. In BD, delusions are often mood congruent (i.e., grandiose delusions during mania in about $50 \%$ of cases) (Pavuluri, Herbener, $\&$ Sweeney, 2004), but need not be (Goes et al., 2007). Children with psychotic mood disorders are often misdiagnosed with schizophrenia, since depressive states may be misinterpreted as negative symptoms, while agitation and flight of ideas due to a manic episode can resemble the disorganization of schizophrenia.

Children who experience extreme stress may have changes in behavior that resemble mania; alternatively, extreme stress may trigger a manic episode in a child who is genetically vulnerable. Sleep loss can precipitate manic episodes in individuals with BD, and there is evidence that sleep loss mediates the link between stress and the onset of mania (MalkoffSchwartz et al., 1998). Therefore, in a youth who has recently encountered a severe stress, clinicians should be alert to the symptoms of post-traumatic stress disorder and particularly wary of assigning the diagnosis of BD.

In a child presenting with a major depressive episode, previous (hypo)manic symptoms should always be assessed, and the child should be observed for the emergence of such symptoms over time, or with antidepressant treatment. The risk of converting from major depressive disorder to BD may be higher in younger cohorts than in adults, with studies reporting rates of developing (hypo)mania ranging from 19 to 49\% (Geller, Zimerman, Williams, Bolhofner, \& Craney, 2001; Kovacs, 1996; Rao et al., 1995). Young, severely depressed patients with psychotic features may be at especially high risk for developing mania (Goldberg, Harrow, \& Whiteside, 2001). Nonetheless, in general one diagnoses and treats the illness with which the child presents, albeit with caution and close monitoring, rather than the one for which he or she may be at risk.

Medical conditions can mimic manic symptoms and must be considered carefully. Conditions that can display manic symptoms are neurological diseases (e.g., head trauma, seizures, multiple sclerosis, stroke), endocrine diseases (e.g., hyperthyroidism, Cushing Syndrome) or reactions to medications or illegal drugs (e.g., steroids, sympathicomimetics, antidepressants, cocaine, methylendioxymethamine) (James \& Javaloyes, 2001). Any adolescent presenting with manic symptoms should be screened for substance abuse. Substance abuse disorders are present in nearly $60 \%$ of adults with BD (Cassidy, Ahearn, \& Carroll, 2001a) but have received little attention in pediatric BD studies. One study found that $32 \%$ of youth with BD had lifetime substance use disorder $(\mathrm{N}=57$, mean age $13.3 \pm 2.4 \mathrm{y})$ (Wilens et al., 2004). This is an important area for future research.

\section{Other clinical considerations}

Once at least one (hypo)manic episode has been established, the overall course of the illness (number and type of previous episodes) should be evaluated for both diagnostic and clinical purposes. As noted above, the ICD-10 requires at least two mood episodes for the diagnosis of $\mathrm{BD}$, of which one must be a (hypo)manic episode, while DSM-IV requires at least one manic or mixed episode for the diagnosis of BD I, or a hypomanic episode plus a major depressive episode in BD II. Depressive symptoms and previous or current episodes of major depression should always be assessed. In addition, even though the literature on pediatric BD has focused predominately on mania, children with BD spend more time depressed than manic, and have more depressive (57.5\%) than (hypo)manic and mixed recurrences (42.5\%) (Axelson et al., 2006; Birmaher et al., 2006). 
Suicidality can be seen in manic, mixed, or depressive episodes, and should always be assessed. Suicide attempts are extremely common in youth with BD. In the COBY study, 35\% of patients with BD I had a lifetime history of suicide attempts (Axelson et al., 2006), and BD is a serious risk factor for completed suicide in adolescents (Goldstein et al., 2005; Welner, Welner, \& Fishman, 1979). Other important risk factors for suicide attempts in BD youth are history of mixed episodes, psychotic symptoms, non-suicidal self-injuries, hospitalizations, panic disorders, and substance abuse disorders (Goldstein et al., 2005).

Severe aggression may be observed in BD. As with suicide, aggression should always be evaluated with direct questions to establish whether the child has experienced homicidal ideation or hallucinations or delusions that could lead to aggressive acts. Parental reports are usually more reliable for a history of aggressive behavior, while child reports are more useful to learn about aggressive impulses and thoughts. As with all other putative manic symptoms, it is important to ascertain whether the aggression, suicidal, or homicidal behavior occurred in the context of a mood episode (i.e., change in mood and associated symptoms).

For both treatment and diagnosis, it is important to follow the youth's symptoms longitudinally. Therefore, it is advisable to have parents and, where appropriate, youth, rate their most prominent symptoms daily. Many instruments are available to allow parents to collect daily or weekly information on mood, sleep pattern, appetite, level of energy/activities, etc. (AACAP, 2007). An example of such a life chart can be found at http://www.dbsalliance.org/pdfs/calendarforweb.pdf (Youngstrom et al., 2005).

Because expert-clinical assessment will always be key in the diagnostic process for $\mathrm{BD}$, all screening should be approached with caution. There is no consensus on a standardized screening instrument for BD. Most recent studies have focused on the Child Behavior Checklist (CBCL; Biederman et al., 1995; Faraone, Althoff, Hudziak, Monuteaux, \& Biederman, 2005; Mick, Biederman, Pandina, \& Faraone, 2003). Children with BD may have high scores $(\mathrm{T}>70)$ on the CBCL Attention Problem, Aggression and Depression/Anxiety subscales (Mick et al., 2003), although this profile is not unique to pediatric BD (Volk \& Todd, 2007; Youngstrom et al., 2006). Possibly, the uneven data on the utility of the CBCL in screening for BD may arise because it does not ascertain episodic symptoms. The Parent Mood Disorder Questionnaire (P-MDQ), the Child Mania Rating Scale (Pauvulun et al., 2006) and the 10-item short form of the Parent General Behavior Inventory (PGBI-SF10) have some potential for screening for BD (Wagner et al., 2006; Youngstrom et al., 2004). For example, in one study the P-MDQ had a sensitivity of $72 \%$ and a specificity of $81 \%$ (Wagner et al., 2006). The Parent General Behavior Inventory Short Form (PGBI-SF10) has a sensitivity of 75\% and specificity of $85 \%$, but performs somewhat less well than the P-MDQ in children 5-10 years old (Youngstrom et al., 2005, 2006). When examining the utility of screening measures, it is important to consider whether the setting in which the screening measure was tested (inpatient, specialty clinic, community clinic, etc.) resembles that in which the clinician wishes to employ it (Youngstrom et al., 2005).

\section{Conclusion}

In the United States, over the last decade there has been a dramatic increase in the rate at which $\mathrm{BD}$ is diagnosed in children and adolescents, leading to a greater number of youth being treated for this condition (Mareno et al., 2007). In assessing BD, it is important for clinicians to adhere consistently to the DSM-IV criteria, ascertaining clear episodes of mania or depression that differ from a child's usual baseline behavior. Children with episodes too brief to meet DSMIV or ICD-10 criteria may warrant a diagnosis of BD-NOS. The nosological status of youth with nonepisodic, impairing irritability is unclear. However, the currently available genetic, physiological, and natural history data do not support assigning them a diagnosis of BD. 
Elation and irritability are characteristic symptoms of mania, but co-occurring illnesses frequently cloud the clinical presentation. Accurate diagnosis requires careful assessment of differential diagnostic features along with longitudinal observation of symptom onset, remission, and recurrence. Further research is needed on the pathophysiology and long-term outcome of DSM-IV BD and of severe, nonepisodic irritability in youth. Research examining the long-term diagnostic stability of BD diagnosed in youths, and inter-site diagnostic studies, are needed. In addition, future research should focus on developmental influences on symptom expression and the presence of co-occurring illnesses in BD. Studies that apply clear phenotypic definitions help to refine treatment by making it possible to ascertain how those with a specific phenotype are likely to respond to a specific intervention.

\section{References}

AACAP. National Institute of Mental Health: National Institute of Mental Health Research Roundtable on prepubertal bipolar disorder. Journal of the American Academy of Child and Adolescent Psychiatry 2001;40:871-878. [PubMed: 11501685]

AACAP. Practice parameter for the assessment and treatment of children and adolescents with bipolar disorder. Journal of the American Academy of Child and Adolescent Psychiatry 2007;46:107-125. [PubMed: 17195735]

American Psychiatric Association. Diagnostic and statistical manual of mental disorders. Vol. 4th edn. American Psychiatric Press, Inc.; Washington, DC: 2001. text rev

Angst J, Cassano G. The mood spectrum: Improving the diagnosis of bipolar disorder. Bipolar Disorders 2005;7(Suppl 4):4-12. [PubMed: 15948762]

Axelson D, Birmaher B, Strober M, Gill MK, Valeri S, Chiappetta L, Ryan N, Leonard H, Hunt J, Iyengar S, Bridge J, Keller M. Phenomenology of children and adolescents with bipolar spectrum disorders. Archives of General Psychiatry 2006;63:1139-1148. [PubMed: 17015816]

Biederman J, Faraone SV, Chu MPB, Wozniak J. Further evidence of a bidirectional overlap between juvenile mania and conduct disorder in children. Journal of the American Academy of Child and Adolescent Psychiatry 1999;38:468-476. [PubMed: 10199120]

Biederman J, Faraone S, Wozniak J, Mick E, Kwon A, Aleardi M. Further evidence of unique developmental phenotypic correlates of pediatric bipolar disorder: Findings from a large sample of clinically referred preadolescent children assessed over the last 7 years. Journal of Affective Disorders 2004;82:S45-S58. [PubMed: 15571789]

Biederman J, Faraone SV, Wozniak J, Mick E, Kwon A, Cayton GA, Clark SV. Clinical correlates of bipolar disorder in a large, referred sample of children and adolescents. Journal of Psychiatric Research 2005;39:611-622. [PubMed: 16009376]

Biederman J, Klein RG, Pine DS, Klein DF. Resolved: Mania is mistaken for ADHD in prepubertal children. Journal of the American Academy of Child and Adolescent Psychiatry 1998;37:1091-1096. [PubMed: 9785721]discussion 1096-1099

Biederman J, Wozniak J, Kiely K, Ablon S, Faraone SV, Mick E, Mundy E, Kraus I. CBCL clinical scales discriminate prepubertal children with structured interview-derived diagnosis of mania from those with ADHD. Journal of the American Academy of Child and Adolescent Psychiatry 1995;34:464-471. [PubMed: 7751260]

Birmaher B, Axelson D, Strober M, Gill MK, Valeri S, Chiappetta L, Ryan N, Leonard H, Hunt J, Iyengar S, Keller M. Clinical course of children and adolescents with bipolar spectrum disorders. Archives of General Psychiatry 2006;63:175-183. [PubMed: 16461861]

Brotman MA, Kassem K, Reising MM, Guyer AE, Dickstein DP, Rich BA, Towbin KE, Pine DS, McMahon FJ, Leibenluft E. Parental diagnoses in youth with narrow phenotype bipolar disorder or severe mood dysregulation. American Journal of Psychiatry 2007;164:1238-1241. [PubMed: 17671287]

Brotman MA, Schmajuk M, Rich BA, Dickstein DP, Guyer AE, Costello EJ, Egger HL, Angold A, Pine DS, Leibenluft E. Prevalence, clinical correlates, and longitudinal course of severe mood dysregulation in children. Biological Psychiatry 2006;60:991-997. [PubMed: 17056393] 
Burke JD, Loeber R, Lahey BB, Rathouz PJ. Developmental transitions among affective and behavioral disorders in adolescent boys. Journal of Child Psychology and Psychiatry 2005;46:1200-1210. [PubMed: 16238667]

Carlson GA. Mania and ADHD: Comorbidity or confusion. Journal of Affective Disorders 1998;51:177187. [PubMed: 10743850]

Cassidy F, Ahearn EP, Carroll BJ. Substance abuse in bipolar disorder. Bipolar Disorders 2001a;3:181188. [PubMed: 11552957]

Cassidy F, Pieper C, Carroll BJ. Subtypes of mania determined by grade of membership analysis. Neuropsychopharmacology 2001b;25:373-383. [PubMed: 11522465]

Costello EJ, Angold A, Burns BJ, Stangl DK, Tweed DL, Erkanli A, Worthman CM. The Great Smoky Mountains Study of Youth. Goals, design, methods, and the prevalence of DSM-III-R disorders. Archives of General Psychiatry 1996;53:1129-1136. [PubMed: 8956679]

Dickstein DP, Nelson EE, McClure EB, Grimley ME, Knopf L, Brotman MA, Rich BA, Pine DS, Leibenluft E. Cognitive flexibility in phenotypes of pediatric bipolar disorder. Journal of the American Academy of Child and Adolescent Psychiatry 2007;46:341-55. [PubMed: 17314720]

Faraone SV, Althoff RR, Hudziak JJ, Monuteaux M, Biederman J. The CBCL predicts DSM bipolar disorder in children: A receiver operating characteristic curve analysis. Bipolar Disorders 2005;7:518-524. [PubMed: 16403177]

Findling RL, Gracious BL, McNamara NK, Young-strom EA, Demeter CA, Branicky LA, Calabrese JR. Rapid, continuous cycling and psychiatric co-morbidity in pediatric bipolar I disorder. Bipolar Disorders 2001;3:202-210. [PubMed: 11552959]

First, MB.; Spitzer, RL.; Gibbon, M.; Williams, J. Structured Clinical Interview for DSM-IV Axis I Disorders, Patient Edition. New York State Psychiatric Institute, Biometrics Research Department; New York: 1995.

Geller B, Tillman R, Bolhofner K. Proposed definitions of bipolar I disorder episodes and daily rapid cycling phenomena in preschoolers, school-aged children, adolescents, and adults. Journal of Child and Adolescent Psychopharmacology 2007;17:217-222. [PubMed: 17489716]

Geller B, Tillman R, Bolhofner K, Zimmerman B, Strauss NA, Kaufman P. Controlled, blindly rated, direct-interview family study of a prepubertal and early adolescent bipolar I disorder phenotype: morbid risk, age of onset, and comorbidity. Archives of General Psychiatry 2006;63:1130-1138. [PubMed: 17015815]

Geller B, Tillman R, Craney JL, Bolhofner K. Four-year prospective outcome and natural history of mania in children with a prepubertal and early adolescent bipolar disorder phenotype. Archives of General Psychiatry 2004;61:459-467. [PubMed: 15123490]

Geller B, Warner K, Williams M, Zimerman B. Prepubertal and young adolescent bipolarity versus ADHD: Assessment and validity using the WASH-U-KSADS, CBCL and TRF. Journal of Affective Disorders 1998a;5:93-100.

Geller B, Williams M, Zimerman B, Frazier J, Beringer L, Warner KL. Prepubertal and early adolescent bipolarity differentiate from ADHD by manic symptoms, grandiose delusions, ultra-rapid or ultradian cycling. Journal of Affective Disorders 1998b;51:81-91. [PubMed: 10743841]

Geller B, Zimerman B, Williams M, Bolhofner K, Craney JL. Bipolar disorder at prospective follow-up of adults who had prepubertal major depressive disorder. American Journal of Psychiatry 2001;158:125-127. [PubMed: 11136645]

Geller B, Zimerman B, Williams M, DelBello MP, Bolhofner K, Craney JL, Frazier J, Beringer L, Nickelsburg MJ. DSM-IV mania symptoms in a prepubertal and early adolescent bipolar disorder phenotype compared to attention-deficit hyperactive and normal controls. Journal of Child and Adolescent Psychopharmacology 2002;12:11-25. [PubMed: 12014591]

Goes FS, Zandi PP, Miao K, McMahon FJ, Steele J, Willour VL, Mackinnon DF, Mondimore FM, Schweizer B, Nurnberger JI Jr, Rice JP, Scheftner W, Coryell W, Berrettini WH, Kelsoe JR, Byerley W, Murphy DL, Gershon ES, Bipolar Disorder Phenome Group. Depaulo JR Jr, McInnis MG, Potash JB. Mood-incongruent psychotic features in bipolar disorder: Familial aggregation and suggestive linkage to 2p11-q14 and 13q21-33. American Journal of Psychiatry 2007;164:236-247. [PubMed: 17267786] 
Goldberg JF, Harrow M, Whiteside JE. Risk for bipolar illness in patients initially hospitalized for unipolar depression. American Journal of Psychiatry 2001;158:1265-1270. [PubMed: 11481161]

Goldstein TR, Birmaher B, Axelson D, Ryan ND, Strober MA, Gill MK, Valeri S, Chiappetta L, Leonard H, Hunt J, Bridge JA, Brent DA, Keller M. History of suicide attempts in pediatric bipolar disorder: Factors associated with increased risk. Bipolar Disorders 2005;7:525-535. [PubMed: 16403178]

Goodwin, FK.; Jamison, KR. Manic-depressive illness: Bipolar disorder and recurrent depression. Vol. 2nd edn. Oxford University Press; New York: 2007.

Guyer AE, McClure EB, Adler AD, Brotman MA, Rich BA, Kimes AS, Pine DS, Ernst M, Leibenluft E. Specificity of face emotion labeling deficits in childhood psychopathology. Journal of Child Psychiatry and Psychology 2007;48:863-871.

James AC, Javaloyes AM. The treatment of bipolar disorder in children and adolescents. Journal of Child Psychology and Psychiatry 2001;42:439-449. [PubMed: 11383960]

Judd LL, Akiskal HS, Schettler PJ, Endicott J, Maser J, Solomon DA, Leon AC, Rice JA, Keller MB. The long-term natural history of the weekly symptomatic status of bipolar I disorder. Archives of General Psychiatry 2002;59:530-537. [PubMed: 12044195]

Kaufman J, Birmaher B, Brent D, Rao U, Flynn C, Moreci P, Williamson D, Ryan N. Schedule for affective disorders and schizophrenia for school-age children-present and lifetime version (K-SADSPL): Initial reliability and validity data. Journal of the American Academy of Child and Adolescent Psychiatry 1997;36:980-988. [PubMed: 9204677]

Kovacs M. Presentation and course of major depressive disorder during childhood and later years of the life span. Journal of the American Academy of Child and Adolescent Psychiatry 1996;35:705-715. [PubMed: 8682751]

Kyte ZA, Carlson GA, Goodyer IM. Clinical and neuropsychological characteristics of child and adolescent bipolar disorder. Psychological Medicine 2006;36:1197-1211. [PubMed: 16566850]

Lapalme M, Hodgins S, LaRoche C. Children of parents with bipolar disorder: A meta-analysis of risk for mental disorders. Canadian Journal of Psychiatry - Revue Canadienne de Psychiatrie 1997;42:623-631. [PubMed: 9288425]

Leibenluft E, Charney DS, Towbin KE, Bhangoo RK, Pine DS. Defining clinical phenotypes of juvenile mania. American Journal of Psychiatry 2003;160:430-437. [PubMed: 12611821]

Leibenluft E, Cohen P, Gorrindo T, Brook JS, Pine DS. Chronic versus episodic irritability in youth: A community-based, longitudinal study of clinical and diagnostic associations. Journal of Child and Adolescent Psychopharmacology 2006;16:456-466. [PubMed: 16958570]

Malkoff-Schwartz S, Frank E, Anderson B, Sherrill JT, Siegel L, Patterson D, Kupfer DJ. Stressful life events and social rhythm disruption in the onset of manic and depressive bipolar episodes: A preliminary investigation. Archives of General Psychiatry 1998;55:702-707. [PubMed: 9707380]

Masi G, Perugi G, Millepiedi S, Mucci M, Toni C, Bertini N, Pfanner C, Berloffa S, Pari C. Developmental differences according to age at onset in juvenile bipolar disorder. Journal of Child and Adolescent Psychopharmacology 2006;16:679-685. [PubMed: 17201612]

Mick E, Biederman J, Pandina G, Faraone SV. A preliminary meta-analysis of the child behavior checklist in pediatric bipolar disorder. Biological Psychiatry 2003;53:1021-1027. [PubMed: 12788247]

Mick E, Spencer T, Wozniak J, Biederman J. Heterogeneity of irritability in attention-deficit/ hyperactivity disorder subjects with and without mood disorders. Biological Psychiatry 2005;58:576-582. [PubMed: 16084859]

Moreno C, Laje G, Blanco C, Jiang H, Schmidt AB, Olfson M. National trends in the outpatient diagnosis and treatment of bipolar disorder in youth. Archives of General Psychiatry 2007;64:1032-1039. [PubMed: 17768268]

Mortensen PB, Pedersen CB, Melbye M, Mors O, Ewald H. Individual and familial risk factors for bipolar affective disorders in Denmark. Archives of General Psychiatry 2003;60:1209-1215. [PubMed: 14662553]

Pavuluri MN, Herbener ES, Sweeney JA. Psychotic symptoms in pediatric bipolar disorder. Journal of Affective Disorders 2004;80:19-28. [PubMed: 15094254]

Pavuluri MN, Henry DB, Devineni B, Carbray JA, Birmaher B. Child mania rating scale: Development, Reliability, and Validity. Journal of the American Academy of Child and Adolescent Psychiatry 2006;45:550-560. [PubMed: 16601399] 
Rao U, Ryan N, Birmaher B, Dahl R, Williamson D, Kaufman J, Rao R, Nelson B. Unipolar depression in adolescents: Clinical outcome in adulthood. Journal of the American Academy of Child and Adolescent Psychiatry 1995;34:566-578. [PubMed: 7775352]

Rende R, Birmaher B, Axelson D, Strober M, Gill M, Valeri S, Chiappetta L, Ryan N, Leonard H, Hunt J, Iyengar S, Keller M. Childhood-onset bipolar disorder: Evidence for increased familial loading of psychiatric illness. Journal of the American Academy of Child and Adolescent Psychiatry 2007;46:197-204. [PubMed: 17242623]

Rich BA, Grimley MB, Schmajuk M, Blair K, Pine DS, Blair RJR, Leibenluft E. Face emotion labeling deficits in children with bipolar disorder and severe mood dysregulation. Development and Psychopathology. (in press)

Rich BA, Schmajuk M, Perez-Edgar KE, Fox NA, Pine DS, Leibenluft E. Different psychophysiological and behavioral responses elicited by frustration in pediatric bipolar disorder and severe mood dysregulation. American Journal of Psychiatry 2007;164:309-317. [PubMed: 17267795]

Singh MK, DelBello MP, Kowatch RA, Strakowski SM. Co-occurrence of bipolar and attention-deficit hyperactivity disorders in children. Bipolar Disorders 2006;8:710-720. [PubMed: 17156157]

Tillman R, Geller B. Definitions of rapid, ultrarapid, and ultradian cycling and of episode duration in pediatric and adult bipolar disorders: A proposal to distinguish episodes from cycles. Journal of Child and Adolescent Psychopharmacology 2003;13:267-271. [PubMed: 14642014]

Tillman R, Geller B, Craney JL, Bolhofner K, Williams M, Zimerman B. Relationship of parent and child informants to prevalence of mania symptoms in children with a prepubertal and early adolescent bipolar disorder phenotype. American Journal of Psychiatry 2004;161:1278-1284. [PubMed: 15229062]

Volk HE, Todd RD. Does the Child Behavior Checklist juvenile bipolar disorder phenotype identify bipolar disorder? Biological Psychiatry 2007;62:115-120. [PubMed: 16950211]

Wagner K, Hirschfeld R, Emslie G, Findling R, Gracious B, Reed ML. Validation of the Mood Disorder Questionnaire for bipolar disorders in adolescents. Journal of Clinical Psychiatry 2006;67:827-830. [PubMed: 16841633]

Welner A, Welner Z, Fishman R. Psychiatric adolescent inpatients: Eight- to ten-year follow-up. Archives of General Psychiatry 1979;36:698-700. [PubMed: 444023]

Wilens T, Biederman J, Kwon A, Ditterline J, Forkner P, Moore H, et al. Risk of substance use disorders in adolescents with bipolar disorder. Journal of the American Academy of Child and Adolescent Psychiatry 2004;43:1380-1386. [PubMed: 15502597]

World Health Organization. International classification of diseases 10th edition: Classification of mental and behavioural disorders. WHO; Geneva: 1992.

Wozniak J, Biederman J, Kiely K, Ablon JS, Faraone SV, Mundy E, Mennin D. Mania-like symptoms suggestive of childhood-onset bipolar disorder in clinically referred children. Journal of the American Academy of Child and Adolescent Psychiatry 1995;34:867-876. [PubMed: 7649957]

Youngstrom E, Meyers O, Youngstrom JK, Calabrese JR, Findling RL. Diagnostic and measurement issues in the assessment of pediatric bipolar disorder: Implications for understanding mood disorder across the life cycle. Development and Psychopathology 2006;18:989-1021. [PubMed: 17064426]

Youngstrom EA, Findling RL, Youngstrom J, Calabrese JR. Toward an evidence-based assessment of pediatric bipolar disorder. Journal of Clinical Child and Adolescent Psychology 2005;34:433-448. [PubMed: 16026213]

Youngstrom EAP, Duax JBA. Evidence-based assessment of pediatric bipolar disorder, Part I: Base rate and family history. Journal of the American Academy of Child and Adolescent Psychiatry 2005;44:712-717. [PubMed: 15968241]

Youngstrom EAP, Findling RLM, Calabrese JRM, Gracious BLM, Demeter C, Bedoya DD, Price M. Comparing the diagnostic accuracy of six potential screening instruments for bipolar disorder in youths aged 5 to 17 years. Journal of the American Academy of Child and Adolescent Psychiatry 2004;43:847-858. [PubMed: 15213586] 
Table 1

Diagnostic and Statistical Manual 4th Edition Text-Revision (DSM-IV-TR) diagnostic criteria for manic episode

A distinct period of abnormally AND persistently elevated, expansive, or irritable mood, lasting at least 1 week (or any duration if hospitalization is necessary)

During the period of mood disturbance, three or more of the following symptoms have persisted (four if mood is only irritable) and have been present to a significant degree:

1) inflated self-esteem or grandiosity

2) decreased need for sleep (e.g. feels rested after only 3 hours of sleep)

3) more talkative than usual or pressure to keep talking

4) flight of ideas or subjective experience that thoughts are racing

5) distractibility (i.e. attention too easily drawn to unimportant or irrelevant external stimuli)

6) increase in goal-directed activity (either socially, at work or school, or sexually) or psychomotor agitation

7) excessive involvement in pleasurable activity with high potential for painful consequences (e.g. engaging in unrestrained buying sprees, sexual indiscretions, or foolish business investments)

Symptoms do not meet criteria for a mixed episode [i.e. during the same 1 week period meets criteria for manic episode AND major depressive episode, including need for symptoms to be present for most of the day for the full week].

Mood disturbance is sufficiently severe to cause marked impairment in occupational functioning or in usual social activities or relationship with others or to necessitate hospitalization to prevent harm to self or others, or there are psychotic symptoms.

Symptoms are not due to the direct physiological effect of a substance (e.g., a drug of abuse, a medication or other treatment) or a general medical condition (e.g., hyperthyroidism). 
Table 2

International Classification of Diseases 10th edn (ICD-10) diagnostic criteria for manic episode

Mood must be predominantly elevated, expansive or irritable, and definitely abnormal for the individual concerned. The mood change must be prominent and sustained for at least 1 week (unless it is severe enough to require hospital admission).

At least three of the following signs must be present (four if the mood is merely irritable) leading to severe interference with personal functioning in daily

living:

1) increased activity or physical restlessness

2) increased talkativeness ('pressure of speech')

3) flight of ideas or the subjective experience that thoughts are racing)

4) loss of normal social inhibitions, resulting in behavior that is inappropriate for the circumstances

5) decreased need for sleep

6) inflated self-esteem or grandiosity

7) distractibility or constant changes in activity or plans

8) behavior that is foolhardy or reckless and whose risks the individual does not recognize, e.g. spending sprees, foolish enterprises, reckless driving 9) marked sexual energy or sexual indiscretions.

There are no hallucinations or delusions, although perceptual disorders may occur (e.g. subjective hypercusis, appreciation of colors as especially vivid). Most commonly used exclusion clause. The episode is not attributable to psychoactive substance use or to any organic mental disorder. 
Table 3

Research diagnostic criteria for severe mood dysregulation (SMD; adapted from Leibenluft et al., 2003)

Inclusion criteria:

Aged 7-17, with the onset of symptoms before age 12

Abnormal mood (specifically anger or sadness), present at least half of the day most days, and of sufficient severity to be noticeable by people in the child's environment (e.g. parents, teachers, peers).

Hyperarousal, as defined by at least three of the following symptoms: insomnia, agitation, distractibility, racing thoughts or flight of ideas, pressured speech, intrusiveness.

Compared to his/her peers, the child exhibits markedly increased reactivity to negative emotional stimuli that is manifest verbally or behaviorally. For example, the child responds to frustration with extended temper tantrums (inappropriate for age and/or precipitating event), verbal rages, and/or aggression toward people or property. Such events occur, on average, at least three times a week.

The symptoms noted in \# ii, iii, and iv above are currently present and have been present for at least 12 months without any symptom-free periods exceeding two months.

The symptoms are severe in at least in one setting (i.e. violent outbursts, assaultiveness at home, school, or with peers). In addition, there are at least mild symptoms (distractibility, intrusiveness) in a second setting.

Exclusion criteria:

The individual exhibits any of these cardinal bipolar symptoms:

Elevated or expansive mood

Grandiosity or inflated self-esteem

Episodically decreased need for sleep

The symptoms occur in distinct periods lasting more than 1 day.

Meets criteria for schizophrenia, schizophreniform disorder, schizoaffective illness, PDD, or PTSD

Meets criteria for substance use disorder in the past three months

IQ<70

The symptoms are due to the direct physiological effects of a drug of abuse, or to a general medical or neurological condition. 